\title{
Communication
}

\section{Activin A and Cell-Surface GRP78 Are Novel Targetable RhoA Activators for Diabetic Kidney Disease}

\author{
Asfia Soomro ${ }^{1, \dagger}{ }^{\dagger}$ Jackie Trink ${ }^{1,+}{ }^{+}$, Kian O ${ }^{\prime}$ Neil $^{1}{ }^{1}$, Renzhong Li ${ }^{1}$, Safaa Naiel ${ }^{2}$, Bo Gao ${ }^{1}$, Kjetil Ask ${ }^{2}$ \\ and Joan C. Krepinsky $1, * \mathbb{D}$ \\ 1 Division of Nephrology, Department of Medicine, McMaster University, Hamilton, ON L8N 4A6, Canada; \\ soomroa@mcmaster.ca (A.S.); trinkj1@mcmaster.ca (J.T.); oneilk9@mcmaster.ca (K.O.); \\ lirenz@mcmaster.ca (R.L.); gaolinbo@hotmail.com (B.G.) \\ 2 Division of Respirology, Department of Medicine, McMaster University, Hamilton, ON L8N 4A6, Canada; \\ naiels@mcmaster.ca (S.N.); askkj@mcmaster.ca (K.A.) \\ * Correspondence: krepinj@mcmaster.ca; Tel.: +1-905-522-1155 (ext. 34991); Fax: +1-905-540-6589 \\ + Contributed equally to this work.
}

Citation: Soomro, A.; Trink, J.; O’Neil, K.; Li, R.; Naiel, S.; Gao, B.; Ask, K.; Krepinsky, J.C. Activin A and Cell-Surface GRP78 Are Novel Targetable RhoA Activators for Diabetic Kidney Disease. Int. J. Mol. Sci. 2021, 22, 2839. https://doi.org/ $10.3390 /$ ijms 22062839

Academic Editor: Katalin Szászi

Received: 3 February 2021

Accepted: 8 March 2021

Published: 11 March 2021

Publisher's Note: MDPI stays neutral with regard to jurisdictional claims in published maps and institutional affiliations.

Copyright: () 2021 by the authors. Licensee MDPI, Basel, Switzerland. This article is an open access article distributed under the terms and conditions of the Creative Commons Attribution (CC BY) license (https:// creativecommons.org/licenses/by/ $4.0 /)$.

\begin{abstract}
Diabetic kidney disease (DKD) is the leading cause of kidney failure. RhoA/Rho-associated protein kinase (ROCK) signaling is a recognized mediator of its pathogenesis, largely through mediating the profibrotic response. While RhoA activation is not feasible due to the central role it plays in normal physiology, ROCK inhibition has been found to be effective in attenuating DKD in preclinical models. However, this has not been evaluated in clinical studies as of yet. Alternate means of inhibiting RhoA/ROCK signaling involve the identification of disease-specific activators. This report presents evidence showing the activation of RhoA/ROCK signaling both in vitro in glomerular mesangial cells and in vivo in diabetic kidneys by two recently described novel pathogenic mediators of fibrosis in DKD, activins and cell-surface GRP78. Neither are present in normal kidneys. Activin inhibition with follistatin and neutralization of cell-surface GRP78 using a specific antibody blocked RhoA activation in mesangial cells and in diabetic kidneys. These data identify two novel RhoA/ROCK activators in diabetic kidneys that can be evaluated for their efficacy in inhibiting the progression of DKD.
\end{abstract}

Keywords: diabetic kidney disease; RhoA; Rho-kinase; fibrosis; activins; cell-surface GRP78

\section{Introduction}

Compared to all other etiologies of progressive kidney disease, diabetic kidney disease (DKD) is the leading cause of morbidity and mortality in developed countries, placing a substantial economic burden on healthcare systems. Current treatment options, including glucose and blood pressure control, use of renin-angiotensin system blockers and, more recently, use of SGLT2 (sodium-glucose cotransporter-2) inhibitors in those with type 2 diabetes, slow disease progression. However, DKD remains the leading cause of kidney failure globally, accounting for almost half of those with end-stage kidney disease requiring dialysis or transplantation [1,2]. A continued improvement in our understanding of the molecular mechanisms underlying its pathogenesis will enable the development of additional complementary therapeutics that will impact DKD progression.

Although pathological changes in DKD ultimately occur in all kidney compartments, glomerular basement membrane thickening and mesangial matrix expansion are the hallmark and earliest manifestations, with the latter due to the increased production of extracellular matrix (ECM) proteins by mesangial cells (MC) [3,4]. RhoA/Rho-associated protein kinase (ROCK) activation has been demonstrated in $\mathrm{MC}$, as well as other glomerular and tubulointerstitial cells, in response to various stimuli relevant to DKD. These include high glucose (HG), growth factors, the profibrotic cytokine transforming growth factor $\beta 1$ 
(TGF $\beta 1$ ) and mechanical signals [5-8]. Indeed, RhoA appears to be a central mediator and integrator of several profibrotic stimuli relevant to diabetes.

RhoA belongs to the Rho family of small GTPases, cycling between an active GTPbound and an inactive GDP-bound form. A conformational change induced by GTP binding allows RhoA to interact with and activate downstream proteins by relieving intramolecular autoinhibitory interactions, with the serine-threonine ROCK, a major downstream mediator, having the most established relevance to DKD $[9,10]$. Through its role as a regulator of cytoskeletal dynamics, as well as its modulation of profibrotic gene expression more directly, RhoA signaling has been shown to regulate the activation of profibrotic signaling pathways and thus the production of ECM [5,10].

The importance of ROCK in DKD has been shown in vivo through pharmacologic or genetic inhibition studies in diabetic mice or rats, with inhibition reducing albuminuria, mesangial expansion, and ECM production [10]. While these studies have suggested for some time that ROCK may be a potential therapeutic target for DKD, there are as yet no clinical trials to evaluate its efficacy despite its clinical evaluation for other disorders [10]. This may be due to its renal hemodynamic effects, particularly in diabetics, which are possibly accentuated when used in combination with inhibitors of the renin-angiotensin system [11]. Similarly, direct inhibition of RhoA is unlikely to be feasible given its importance in normal cellular physiology. A potential alternative approach may be to target distinct activators of RhoA signaling that are selective for DKD.

Recently, two novel mediators of the pathogenesis of DKD have emerged. These are the upregulation of, and signaling by, TGF $\beta$ superfamily members known as activins, as well as the HG-induced translocation of the intracellular protein GRP78 to the cell surface to act as an initiator of profibrotic signaling. Both are significantly activated in DKD, with a minimal presence in normal kidneys $[12,13]$. Whether they integrate with RhoA signaling, however, is unknown. Therefore, in this study, we assess their ability to activate RhoA/ROCK in cultured MC and in DKD. We propose that an approach to diminishing renal fibrosis via RhoA/ROCK attenuation is in the single or combined inhibition of these novel targets.

\section{Materials and Methods}

\subsection{Cell Culture}

Primary mouse MC were isolated as described previously [14] and cultured in Dulbecco's modified Eagle medium supplemented with $20 \%$ fetal bovine serum, streptomycin $(100 \mu \mathrm{g} / \mathrm{mL})$ and penicillin $(100 \mu \mathrm{g} / \mathrm{mL})$. They were grown at $37{ }^{\circ} \mathrm{C}$ in $95 \% \mathrm{O}_{2}$ and $5 \% \mathrm{CO}_{2}$. $\mathrm{MC}$ were serum deprived in medium with $1 \%$ bovine serum albumin prior to treatment.

\subsection{Protein Extraction and Immunoblotting}

Whole-cell lysates were collected as previously described [8]. For biotinylation experiments, MC were incubated with $1 \mathrm{mg} / \mathrm{mL}$ EZ-linked Sulfo-Biotin (Pierce) for $30 \mathrm{~min}$ followed by $0.1 \mathrm{M}$ glycine in PBS to remove excess Sulfo-Biotin, then whole-cell lysates were collected and incubated overnight in a 50\% NeutrAvidin slurry (Fisher) to pull down biotin-tagged proteins. Immunoprecipitates were assessed with SDS-PAGE and immunoblotted for surface proteins. The following antibodies were used for immunoblotting: $\alpha$-smooth muscle actin ( $\alpha$ SMA) (Pierce, 1:5000), phosphorylated myosin phosphatase target (pMYPT) Thr696 (Cell Signaling; 1:1000), fibronectin (FN) (BD Biosciences, 1:1000), total RhoA (Santa Cruz, 1:500), MTJ-1 (Santa Cruz, 1:1000), GRP78 (BD Biosciences, 1:1000), PDGFR $\beta$ (Cedarlane, 1:1000), vinculin (Sigma, 1:1000) and tubulin (Santa Cruz, 1:5000).

\subsection{RhoA Activity}

Active RhoA was immunoprecipitated from freshly lysed cells using GST-tagged Rhotekin RBD (Upstate), which binds specifically to GTP-bound RhoA. To detect active, GTP-bound RhoA in kidneys, immunohistochemistry was conducted on paraffin embedded kidney sections $(4 \mu \mathrm{m})$ using the conformation-sensitive RhoA antibody (New East 
Biosciences, 1:275) after heat-induced epitope retrieval (30 min steaming in citric acid). Twenty images were then taken at $60 \times$ for each section, quantified using Image J software, and values averaged to produce one value per image. This value was used for statistical analysis as described below.

\subsection{Animal Studies}

All studies were conducted in accordance with McMaster University and the Canadian Council on Animal Care guidelines. Male C57BL/6-InsAkita/J (Jackson Labs) type 1 diabetic mice and their wild-type controls were injected intraperitoneally (IP) with follistatin $(3 \mu \mathrm{g})$ or the vehicle every other day from 6 to 18 weeks, as previously described [13]. Male CD1 mice (Charles River) underwent left nephrectomy at 9 weeks, followed one week later by IP injection of $200 \mathrm{mg} / \mathrm{kg}$ streptozotocin to induce type 1 diabetes. Control mice received an equal volume of citrate buffer. Mice confirmed to be diabetic were treated IP with the cell-surface GRP78-neutralizing antibody C38 (generously provided by S. Pizzo [15]) or isotype IgG2b (BioXCell) at an initial dose of $200 \mu \mathrm{g}$ followed by $100 \mu \mathrm{g}$ weekly for a total of 12 weeks. Formalin-fixed tissue was used for immunohistochemistry studies.

\subsection{Transfection, Luciferase and siRNA}

MC were plated at $60-70 \%$ confluence and transfected with $0.5 \mu \mathrm{g}$ of the alpha smooth muscle actin promoter ( $\alpha \mathrm{SMA}$ ) luciferase reporter construct (pGal3- $\alpha$-SMAp-luc), a generous gift from Dr. A. Kapus and $0.05 \mu \mathrm{g}$ pCMV $\beta$-galactosidase (Clontech) using Effectene (Qiagen). After the cells were harvested, luciferase and $\beta$-galactosidase activities were measured using kits from Promega. For siRNA transfection, MC were plated at $50 \%$ confluence and transfected with $100 \mathrm{nM}$ MTJ-1 siRNA (Thermo Fisher). The following day, cells were serum deprived prior to treatment.

\subsection{RNA Extraction and $q P C R$}

RNA was extracted from flash-frozen kidney sections using the RNeasy Plus Mini Kit (Qiagen). RNA was reverse transcribed using qScript Supermix Reagent (Quanta Biosciences) and quantitative real time PCR was performed using the Power SYBR Green PCR Master Mix on the Applied Biosystems Vii 7 Real-Time PCR System. Primer sequences used were as follows: CHOP forward 5'-GGAAACAGAGTGGTCATTCCC- $3^{\prime}$ and reverse $5^{\prime}$ CTGCTTGAGCCGTTCATTCTC- $3^{\prime}$ and IRE1 $\alpha$ forward $5^{\prime}$-CCATCGAGCTGTGTGCAG- $3^{\prime}$ and reverse $5^{\prime}$-TGTTGAGGGAGTGGAGGTG- ${ }^{\prime}$. mRNA expression levels were determined relative to $18 \mathrm{~S}$ of the same sample using the $\Delta \Delta \mathrm{CT}$ method.

\subsection{Statistical Analysis}

One-way ANOVA was used for analysis, with Tukey's HSD used for post hoc testing and $p<0.05$ considered significant. Data were presented as mean \pm SEM.

\section{Results}

\subsection{RhoA Mediates the Profibrotic Effects of Activins in DKD}

Activins are emerging as important mediators in the pathogenesis of DKD [16]. These members of the transforming growth factor $\beta 1$ (TGF $\beta 1$ ) superfamily are glycoprotein dimers composed of two $\beta$-subunits of inhibin linked by disulfide bonds. Five isoforms have been identified in mammals, including activins $\mathrm{A}, \mathrm{B}, \mathrm{AB}, \mathrm{C}$, and $\mathrm{E}$, with activin $\mathrm{A}$ being the most well studied to date. Activin $\mathrm{A}$ is important during kidney development, but is not present in the normal adult kidney. Activin B is also not normally present in adult kidneys, but its role in development and disease is as yet relatively unknown, with little information available for the other isoforms [17,18]. Analogous to TGF $\beta 1$, activins A and B signal through a complex of type I and II receptors to activate Smad3, with consequent regulation of gene expression through the Smad-binding element $[17,18]$. Interestingly, in various cells, including renal fibroblasts and $\mathrm{MC}$, activins have also been shown to be critical for the profibrotic response to TGF $\beta 1$ [14,19-21], a cytokine central to the pathogenesis of 
DKD [22], although the mechanism underlying this has not been defined as of yet. We and others have recently shown activin A to be induced in DKD $[13,23]$ and to be a prominent mediator of HG-induced profibrotic responses in MC. We have also recently observed an increase in activin B in DKD (unpublished). Importantly, the activin inhibitor follistatin improved DKD in type 1 diabetic Akita mice [13].

While the activation of RhoA/Rho-kinase by HG in MC and in DKD has been well established [5,10], whether activins are needed for this is as yet unknown. In non-malignant cells, activin B was shown to induce RhoA activation [24-26]. Whether activin A similarly induces its activation and whether this occurs in MC have not been determined as of yet. We therefore tested both activins for their ability to induce RhoA signaling. Figure $1 \mathrm{~A}, \mathrm{~B}$ show that both activins induced RhoA and downstream ROCK activation, with the latter assessed by phosphorylation of its target protein myosin phosphatase target subunit 1 (pMYPT1) at Thr696. Since increased expression of $\alpha$-smooth muscle actin $(\alpha \mathrm{SMA})$ is a characteristic of activated MC, which synthesize matrix proteins [27], and RhoA/ROCK signaling is known to regulate $\alpha \mathrm{SMA}$ transcription [28], we next tested the ability of activins to increase $\alpha$ SMA production in MC. Figure $1 C$,D show that activin A induced $\alpha \mathrm{SMA}$ promoter activation and protein expression in $\mathrm{MC}$, and that this was prevented by ROCK inhibition with either Y27632 or HA1077. We further confirmed that activin Ainduced upregulation of the profibrotic protein fibronectin was also attenuated by Y27632 (Figure 1D).

These data suggested that RhoA signaling may mediate activin profibrotic responses in DKD. This was tested using the activin inhibitor follistatin. As seen in Figure 1E,F, follistatin effectively blocked HG-induced RhoA and downstream ROCK activation. As we have shown that follistatin inhibits DKD in type 1 diabetic Akita mice without affecting blood glucose levels [13], we next assessed the relevance of these findings in vivo. Using an antibody specific to active RhoA, immunohistochemistry confirmed that activation of RhoA, which is increased in the kidneys of diabetic mice, was attenuated by treatment with follistatin (Figure 1G). Taken together, these data indicate that RhoA is an important mediator of activin responses both in vitro and in vivo. 
A

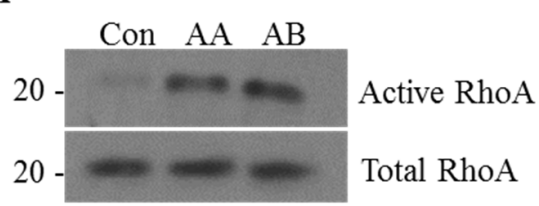

C

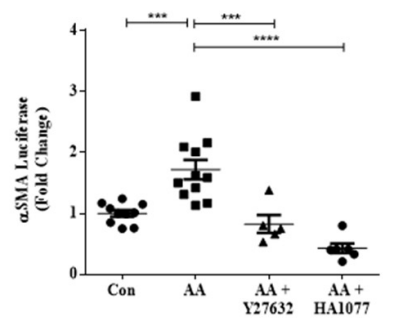

$\mathbf{E}$

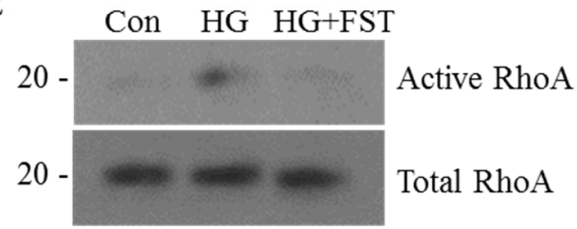

G

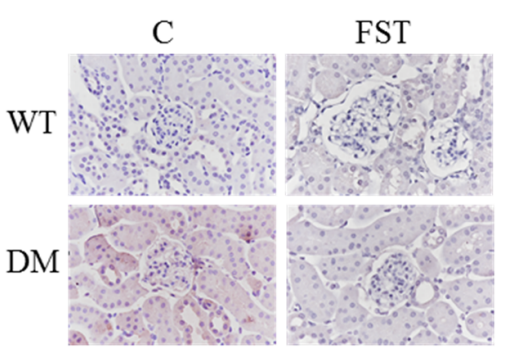

B

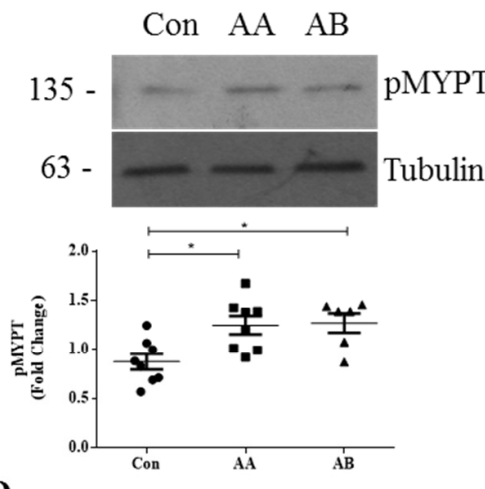

D
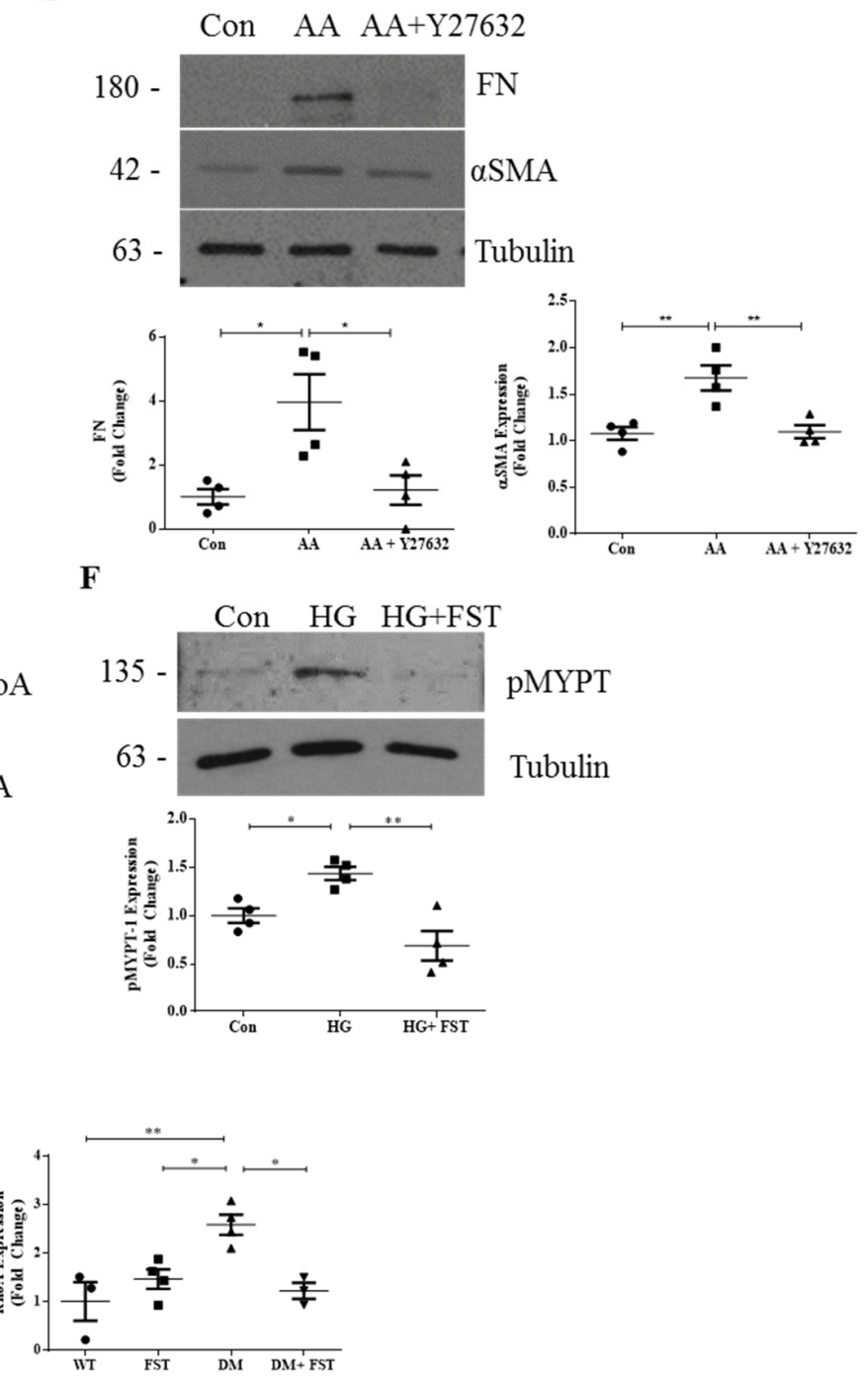

Figure 1. RhoA mediates the profibrotic effects of activins in diabetic kidney disease (DKD). (A) Activin A (20 ng/mL, $3 \mathrm{~h}$ ) and activin B (20 ng/mL, $3 \mathrm{~h})$ both activated RhoA in mesangial cells (MC) $(n=2)$. (B) Activation of downstream Rho-kinase was also seen, assessed by phosphorylation of myosin phosphatase target (MYPT) (pMYPT Thr696) in MC $(n=6-8 * p<0.05)$. (C) Rho-kinase inhibition with Y27632 $(10 \mu \mathrm{M})$ or HA1077 $(10 \mu \mathrm{M})$ prevented activin A $(20 \mathrm{ng} / \mathrm{mL})$-induced $\alpha$-smooth muscle actin $(\alpha \mathrm{SMA})$ promoter luciferase activation $\left(n=6-11^{* * *} p<0.001,{ }^{* * * *} p<0.0001\right)$ and (D) protein expression of both $\alpha \mathrm{SMA}$ and the fibrotic protein fibronectin (FN) $\left(n=4,{ }^{*} p<0.05,{ }^{* *} p<0.01\right)$. (E) The activin inhibitor follistatin (FST, $\left.500 \mathrm{ng} / \mathrm{mL}\right)$ prevented high glucose (HG) (3 h)-induced RhoA activation $(n=2)$ and (F) Rho-kinase activation $\left(n=3,{ }^{*} p<0.05,{ }^{* *} p<0.01\right)$. (G) RhoA activation in kidneys was also significantly inhibited by follistatin in type 1 diabetic Akita mice, as assessed by IHC with an antibody which specifically detects active RhoA $\left(n=4,{ }^{*} p<0.05,{ }^{* *} p<0.01\right)$. 


\subsection{Cell-Surface GRP78 Mediates HG-Induced RhoA Activation}

We have recently identified cell-surface (cs)GRP78 as a novel pathologic signaling receptor in DKD [12]. Endogenously, GRP78 is well known as an endoplasmic reticulum (ER) chaperone responsible for proper protein folding and homeostasis. More recently, GRP78 has also been shown to translocate to the surface of various cell types under conditions of ER stress. While this has been best described in cancer cells, we have also shown this to occur in response to HG in MC and in glomeruli from diabetic mice [12,29,30]. Once at the cell surface, GRP78 promotes profibrotic PI3K/Akt activation to potentiate the accumulation of ECM proteins in MC exposed to HG [12]. Recently, RhoA/ROCKmediated PI3K/Akt activation via csGRP78 has been shown in pancreatic cancer cells [31]. We were therefore interested in determining whether RhoA signaling was also activated downstream of csGRP78 in response to HG.

We and others previously showed that cell-surface GRP78 signaling can be inhibited with antibodies that target its $C$ terminus $[12,15]$. We thus tested the effects of a C-terminus-targeting antibody (C38) on HG-induced RhoA activation. In Figure 2A, immunofluorescence using an antibody specific to active RhoA shows that C38, but not control IgG, inhibited HG-induced RhoA activation. This was confirmed using an assay to immunoprecipitate active RhoA (Figure 2B). Similar inhibition of HG-induced ROCK activation by C38 was seen, assessed by phosphorylation of MYPT (Figure 2C). Downregulation by siRNA of MTJ-1, a co-chaperone required for cell-surface translocation of GRP78 [32], further supported a role for csGRP78 in HG-induced ROCK activation (Figure 2D). Given the important role of RhoA/ROCK in cytoskeletal reorganization and intracellular trafficking [33], we further assessed whether the movement of GRP78 to the cell surface in response to longer-term HG exposure could also be regulated by RhoA signaling. Interestingly, Figure 2E shows that HG-induced csGRP78 localization, as assessed by the biotinylation of cell-surface proteins followed by immunoblotting for GRP78, was prevented by the ROCK inhibitor Y27632. These data implicate a bidirectional dependence of csGRP78 and RhoA in HG, whereby csGRP78 both serves as an upstream regulator of RhoA activity, and also requires its signaling for movement to the cell surface.

Finally, to test the in vivo relevance of this model, we assessed RhoA activity by immunohistochemistry in type 1 diabetic CD1 mice treated with the $\mathrm{C} 38$ antibody, as described in the Materials and Methods. Treatment did not affect glucose levels (con $10.1 \pm 1.4 \mathrm{mM}$, $\mathrm{DM} 32.9 \pm 0.3 \mathrm{mM}, \mathrm{DM}+\mathrm{C} 3831.6 \pm 0.9 \mathrm{mM}, \mathrm{DM}+\mathrm{IgG} 29.3 \pm 0.8 \mathrm{mM})$. Figure $2 \mathrm{~F}$ shows that csGRP78 inhibition, but not the isotype IgG, attenuated RhoA activation in diabetic kidneys. Taken together, RhoA/ROCK signaling is also a downstream mediator of csGRP78-induced profibrotic responses, likely through regulation of PI3K/Akt signaling [12,31]. Finally, given the involvement of GRP78 in ER stress, we further assessed if the attenuation of RhoA activation observed with the C38 antibody was also associated with a reduction in ER stress. We assessed the transcript levels of well-established ER stress response genes, CHOP and IRE1 $\alpha$ [29]. As shown in Appendix A Figure A1, these were significantly increased in diabetic mice, but were unaffected by treatment with C38, suggesting that inhibition of csGRP78 does not affect ER stress in this model. 
A

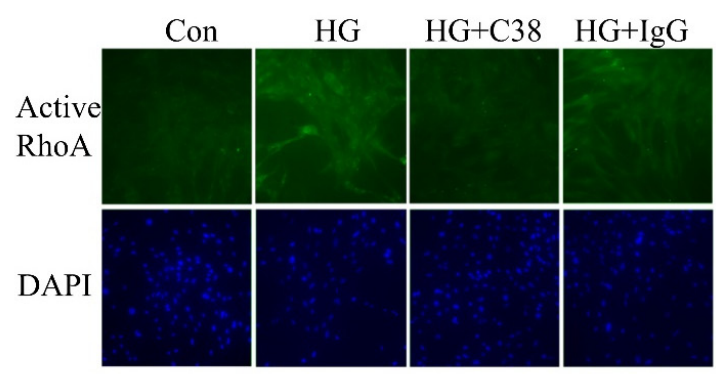

C
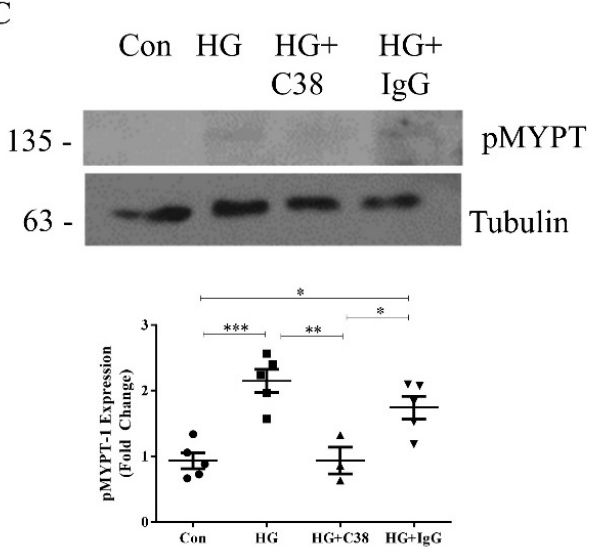

E
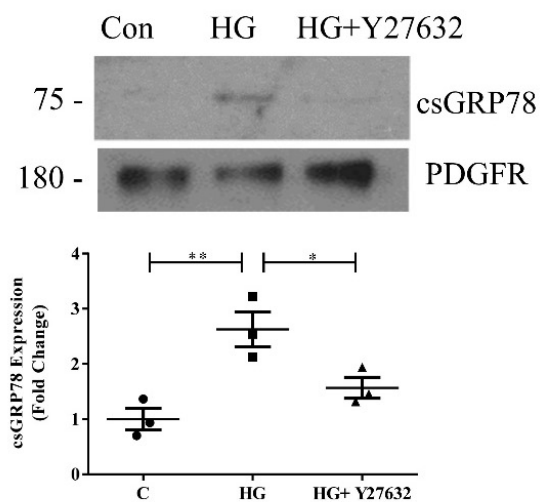

B

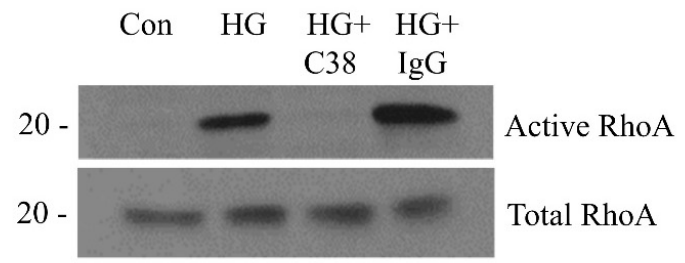

D

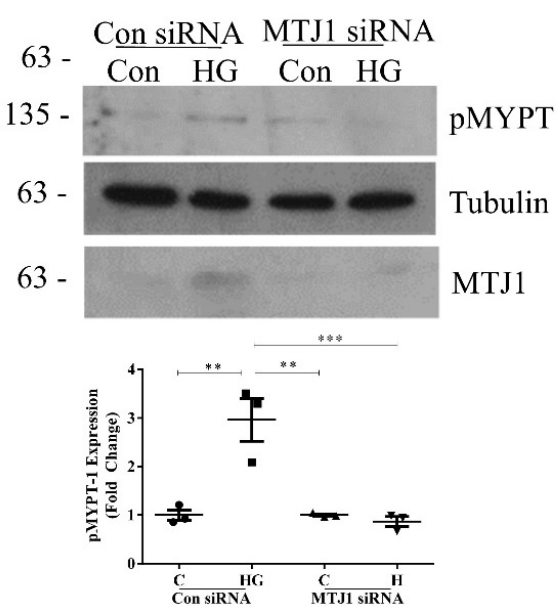

F
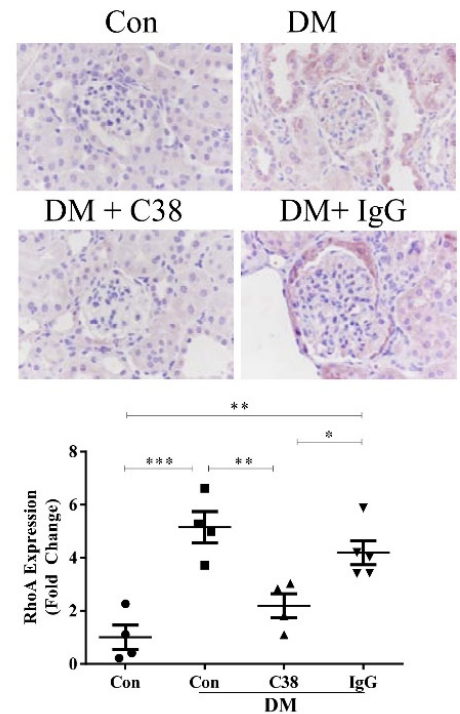

Figure 2. Cell-surface GRP78 mediates HG-induced RhoA activation. Inhibition of cell-surface GRP78 with an antibody specific to its C-terminus (C38, $2 \mu \mathrm{g}$ ), but not control IgG, attenuated HG-induced RhoA activation, assessed by immunofluorescence using an active RhoA-specific antibody (A) and pull-down and immunoblotting of active RhoA (B). (C) Immunoblotting confirmed inhibition of HG-induced Rho-kinase activation by C38, assessed by phosphorylation of MYPT $\left(n=5,{ }^{*} p<0.05,{ }^{* *} p<0.01,{ }^{* * *} p<0.001\right)$. (D) siRNA knockdown of MTJ-1 to prevent GRP78 localization to the cell-surface also inhibited Rho-kinase activation by HG $\left(n=3,{ }^{* *} p<0.01,{ }^{* * *} p<0.001\right)$. (E) Conversely, HG (48 h)-induced

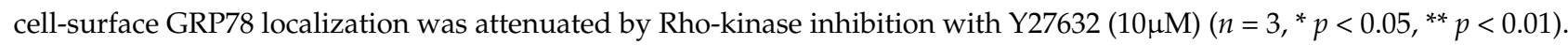
(F) RhoA activation was assessed by immunohistochemistry in kidneys of uninephrectomized CD1 mice made diabetic by streptozotocin. Activation was significantly inhibited by cell-surface GRP78 inhibition with C38 compared to control IgG $\left(n=4, * p<0.05,{ }^{* *} p<0.01, * * * 0<0.001\right)$. 


\section{Discussion and Conclusions}

DKD is the leading cause of end-stage kidney disease. Despite the significant recent advancement in treatment options with the advent of SGLT2 inhibitors, ongoing efforts to develop additive therapies that can prevent the progression of DKD are needed. The central importance of RhoA/ROCK signaling in the pathogenesis of DKD has been well established in cell culture studies and animal models. However, this has not as yet translated into clinical practice. RhoA appears to integrate numerous profibrotic signals relevant to the diabetic state and, in this study, we show that signaling through both activins and csGRP78 also relies on RhoA/ROCK activation. Importantly, we show that their inhibition in vivo efficiently suppresses RhoA activation in diabetic kidneys, suggesting that their targeting may be a novel and effective means of inhibiting the progression of DKD.

Two ROCK isoforms exist, but a greater understanding is needed with regard to their individual roles in DKD. In cell culture, differential effects of these isoforms have been observed in different cells. For example, ROCK2, but not ROCK1, deletion inhibited TGF $\beta 1$-induced profibrotic responses in MC [34]. Conversely, ROCK1 deletion attenuated HG-induced apoptosis in podocytes and endothelial cells [35]. Thus, it would appear that inhibition of both isoforms may be needed for DKD protection. Indeed, the nonselective ROCK inhibitor fasudil protected against DKD in both type 1 and 2 diabetic models $[5,36,37]$, although it is important to note that it may inhibit other serine/threonine kinases at similar or higher concentrations [38]. However, knockout or inhibition of individual isoforms has also shown overall in vivo benefits. ROCK1 knockout mice had decreased albuminuria, mesangial matrix expansion, glomerular basement membrane thickness and loss of podocytes in both type 1 (streptozotocin-induced) and $2(\mathrm{db} / \mathrm{db})$ diabetic mice $[39,40]$. The recently developed selective ROCK2 inhibitor KD025 was also shown to attenuate albuminuria and glomerular fibrosis in $\mathrm{db} / \mathrm{db}$ mice [35]. It thus appears that in vivo inhibition of either isoform provides benefits. However, ROCK is important to the renal regulation of blood flow, particularly in diabetic animals [11]. While it is not known whether this is isoform specific as of yet, it remains to be seen whether ROCK inhibitors, in clinical practice, could safely be used and combined with inhibitors of the renin-angiotensin system or SGLT2 inhibitors that also have glomerular hemodynamic effects.

The direct targeting of RhoA is unlikely to be feasible given the important role of this GTPase in fundamental cellular processes. Indeed, RhoA knockout is embryonically lethal in mice [9]. Furthermore, podocyte-specific RhoA activation and inhibition both caused podocyte injury [41], illustrating the requirement for a fine balance in the activity of this pathway. Furthermore, there are several RhoA effectors other than ROCK, such as protein kinase $\mathrm{N}(\mathrm{PKN})$ and $\mathrm{mDia}$, the roles of which have not as yet been investigated in DKD [9]. Indeed, PKN is closely related to protein kinase $C$, which has a well-established pathogenic role in DKD [42]. We thus propose that targeting other regulatory factors activating RhoA signaling may better modulate its activity to reduce pathologic activation while maintaining its ability to function in homeostasis.

An important activator of RhoA/ROCK is the profibrotic cytokine TGF $\beta 1$, a major and well recognized mediator of DKD $[7,42,43]$. Attempts have been made to target TGF $\beta$ clinically. However, it too has important functions which lead to adverse effects when inhibited. When used at tolerated doses, a recent clinical trial showed that a TGF $\beta 1$-neutralizing antibody was not clinically effective at slowing DKD, likely due to incomplete TGF $\beta 1$ neutralization in an effort to limit adverse effects [44]. Recently, activins have emerged as potentially important profibrotic mediators in DKD and other renal diseases [13,16]. Interestingly, although activins A and B signal through the same Smad mediators as TGF $\beta 1$, studies in various renal and other cells have shown that the profibrotic effect of TGF $\beta 1$ is dependent on the presence of activins [14,19-21]. The mechanism underlying this is not as yet known, but given that the expression of activins in normal adult kidneys is very low or absent, with significant upregulation in DKD, these cytokines offer an alternative therapeutic target for TGF $\beta 1 /$ RhoA inhibition. 
Previous studies have shown that activin B activates RhoA/ROCK to regulate cell movement, cytoskeletal reorganization and wound healing $[24,25,45]$. In this study, we showed that activins A and B both directly regulate RhoA and downstream ROCK activity. Furthermore, their inhibition with follistatin, which we have previously shown to ameliorate DKD in type 1 diabetic mice [13], also inhibits both HG-induced RhoA/ROCK activation in MC and RhoA activation in diabetic kidneys. These data suggest that activins may mediate profibrotic responses through RhoA/ROCK signaling. Future studies are needed to investigate the crosstalk between Smad and RhoA/ROCK signaling by activins in the diabetic setting.

We have recently identified csGRP78 as an additional profibrotic mediator in DKD, the expression of which is absent in normal kidneys [12]. Thus, akin to activin expression in diabetic kidneys, csGRP78 may provide an alternative disease-specific target. In this study, we identify the involvement of csGRP78 in RhoA/ROCK activation by HG in MC and in diabetic kidneys. The activation of RhoA/ROCK by csGRP78 has also recently been shown in pancreatic cancer cells, where it mediated downstream PI3K/Akt activation [46]. Since we have previously shown that csGRP78 is required for PI3K/Akt activation, a known profibrotic pathway in response to HG [12,47], it is likely that RhoA/ROCK signaling lies upstream of this. Interestingly, cell-surface expression of GRP78 was also significantly reduced by ROCK inhibition, suggesting that RhoA/ROCK activation promotes further translocation of GRP78 to the cell surface. The regulation of cellular trafficking through cytoskeletal changes by RhoA [33] is likely to be important for these observations, but this needs to be confirmed experimentally. Alternatively, ROCK inhibition was shown to downregulate the expression of cellular GRP78 in human pulmonary microvascular endothelial cells [48]. A reduction in the total pool of GRP78 may lead to reduced cellsurface expression, although we have not observed any effects of HG on total GRP78 expression [12]. Altogether, this suggests an important role for csGRP78 in mediating RhoA/ROCK signaling as an important regulator of DKD pathogenesis.

In conclusion, our data identify two potential novel alternative approaches to targeting RhoA/ROCK-dependent profibrotic signaling in DKD. Here, both activins A/B and csGRP78 are viable potential candidates for anti-fibrotic therapeutics. Considering the important role of RhoA/ROCK in normal cellular function, these targets are attractive given their relative absence in normal kidneys. Indeed, several options are available and can be evaluated for targeting activins in DKD, including follistatin, ligand traps and neutralizing antibodies [16]. Of these, follistatin was shown to reduce DKD in a preclinical model [13], and some, such as ligand traps and neutralizing antibodies, are already in clinical development for other disorders [16]. Whether targeting csGRP78 in vivo benefits DKD must be tested, and studies using the C38 antibody are ongoing in our lab. A greater understanding of the mechanism by which csGRP78 is activated by HG would also assist in developing novel therapeutics in order to target this particular protein.

Author Contributions: Conceptualization, A.S., J.T. and J.C.K.; Methodology, A.S., J.T., S.N., K.A. and J.C.K.; Experiments, A.S., J.T., K.O., R.L., B.G. and S.N.; Analysis and Data Curation, A.S., J.T.; Writing-Original Draft Preparation, A.S., J.T.; Writing—Review \& Editing, J.C.K.; Funding Acquisition, J.C.K. All authors have read and agreed to the published version of the manuscript.

Funding: This work was supported by the Canadian Institutes of Health Research (CIHR) (JCK), MOP 136,868 and PJT-148628 and Kidney Foundation of Canada (JCK), KFOC180020. We acknowledge the support of St. Joseph's Healthcare for nephrology research.

Institutional Review Board Statement: The study was conducted according to the guidelines of the Declaration of Helsinki and approved by the Institutional Review Board (or Ethics Committee) of McMaster University (protocol codes 16-07-27, 3 August 2016 and 18-07-30, 29 August 2018).

Informed Consent Statement: Not applicable.

Data Availability Statement: Data are contained within the article and Appendix A. 
Acknowledgments: We thank A. Kapus for providing pGal3- $\alpha$-SMAp-luc and S. Pizzo for providing the C38 GRP78 antibody. We also thank Paranta Biosciences (Australia) for providing follistatin).

Conflicts of Interest: The authors declare no conflict of interest.

\section{Appendix A}

A

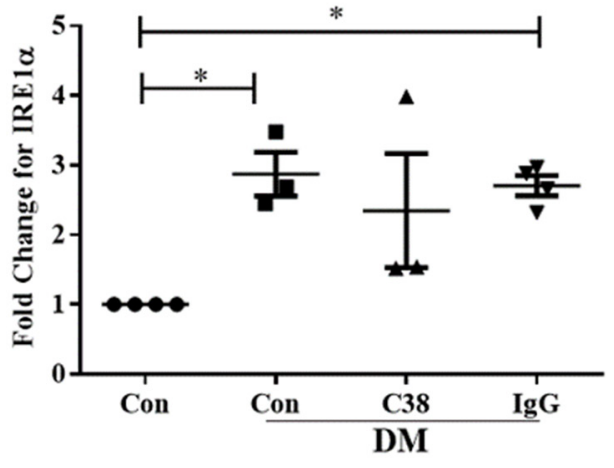

B

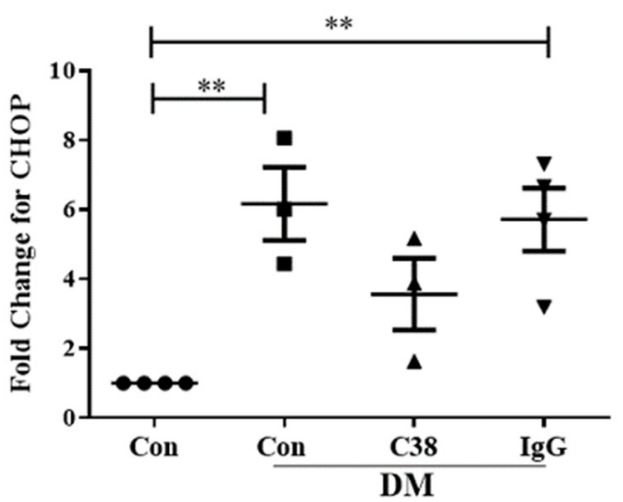

Figure A1. Cell surface GRP78 inhibition does not attenuate ER stress. Transcript levels for the ER stress response genes IRE1 $\alpha(\mathbf{A})$ and CHOP $(\mathbf{B})$ were assessed by qPCR. The increase seen in diabetic mice was not attenuated by treatment with C38 $\left(n=4,{ }^{*} p<0.05,{ }^{* *} p<0.01\right)$.

\section{References}

1. Alicic, R.Z.; Rooney, M.T.; Tuttle, K.R. Diabetic Kidney Disease: Challenges, progress, and possibilities. Clin. J. Am. Soc. Nephrol. 2017, 12, 2032-2045. [CrossRef]

2. Tuttle, K.R.; Brosius, F.C.; Cavender, M.A.; Fioretto, P.; Fowler, K.J.; Heerspink, H.J.; Manley, T.; McGuire, D.K.; Molitch, M.E.; Mottl, A.K.; et al. SGLT2 Inhibition for CKD and Cardiovascular Disease in Type 2 Diabetes: Report of a Scientific Workshop Sponsored by the National Kidney Foundation. Am. J. Kidney Dis. 2020, 77. [CrossRef]

3. Mauer, S.M.; Steffes, M.W.; Ellis, E.N.; Sutherland, D.E.; Brown, D.M.; Goetz, F.C. Structural-functional relationships in diabetic nephropathy. J. Clin. Investig. 1984, 74, 1143-1155. [CrossRef]

4. Caramori, M.L.; Parks, A.; Mauer, M. Renal Lesions Predict Progression of Diabetic Nephropathy in Type 1 Diabetes. J. Am. Soc. Nephrol. 2013, 24, 1175-1181. [CrossRef] [PubMed]

5. Peng, F.; Wu, D.; Gao, B.; Ingram, A.J.; Zhang, B.; Chorneyko, K.; McKenzie, R.; Krepinsky, J.C. RhoA/Rho-Kinase Contribute to the Pathogenesis of Diabetic Renal Disease. Diabetes 2008, 57, 1683-1692. [CrossRef]

6. $\quad$ Akiyama, N.; Naruse, K.; Kobayashi, Y.; Nakamura, N.; Hamada, Y.; Nakashima, E.; Matsubara, T.; Oiso, Y.; Nakamura, J. High glucose-induced upregulation of Rho/Rho-kinase via platelet-derived growth factor receptor- $\beta$ increases migration of aortic smooth muscle cells. J. Mol. Cell. Cardiol. 2008, 45, 326-332. [CrossRef] [PubMed]

7. Peng, F.; Zhang, B.; Wu, D.; Ingram, A.J.; Gao, B.; Krepinsky, J.C. TGF $\beta$-induced RhoA activation and fibronectin production in mesangial cells require caveolae. Am. J. Physiol. Physiol. 2008, 295, F153-F164. [CrossRef]

8. Krepinsky, J.C.; Ingram, A.J.; Tang, D.; Wu, D.; Liu, L.; Scholey, J.W. Nitric Oxide Inhibits Stretch-Induced MAPK Activation in Mesangial Cells Through RhoA Inactivation. J. Am. Soc. Nephrol. 2003, 14, 2790-2800. [CrossRef] [PubMed]

9. Thumkeo, D.; Watanabe, S.; Narumiya, S. Physiological roles of Rho and Rho effectors in mammals. Eur. J. Cell Biol. 2013, 92, 303-315. [CrossRef]

10. Matoba, K.; Takeda, Y.; Nagai, Y.; Sekiguchi, K.; Yokota, T.; Utsunomiya, K.; Nishimura, R. The Physiology, Pathology, and Therapeutic Interventions for ROCK Isoforms in Diabetic Kidney Disease. Front. Pharmacol. 2020, 11. [CrossRef]

11. Komers, R.; Oyama, T.T.; Beard, D.R.; Anderson, S. Effects of systemic inhibition of Rho kinase on blood pressure and renal haemodynamics in diabetic rats. Br. J. Pharmacol. 2010, 162, 163-174. [CrossRef] [PubMed]

12. Van Krieken, R.; Mehta, N.; Wang, T.; Zheng, M.; Li, R.; Gao, B.; Ayaub, E.; Ask, K.; Paton, J.C.; Paton, A.W.; et al. Cell surface expression of 78-kDa glucose-regulated protein (GRP78) mediates diabetic nephropathy. J. Biol. Chem. 2019, 294, 7755-7768. [CrossRef] [PubMed]

13. Zhang, D.; Gava, A.L.; Van Krieken, R.; Mehta, N.; Li, R.; Gao, B.; Desjardins, E.M.; Steinberg, G.R.; Hawke, T.; Krepinsky, J.C. The caveolin-1 regulated protein follistatin protects against diabetic kidney disease. Kidney Int. 2019, 96, 1134-1149. [CrossRef]

14. Mehta, N.; Zhang, D.; Li, R.; Wang, T.; Gava, A.; Parthasarathy, P.; Gao, B.; Krepinsky, J.C. Caveolin-1 regulation of Sp1 controls production of the antifibrotic protein follistatin in kidney mesangial cells. Cell Commun. Signal. 2019, 17, 37. [CrossRef]

15. De Ridder, G.G.; Ray, R.; Pizzo, S.V. A murine monoclonal antibody directed against the carboxyl-terminal domain of GRP78 suppresses melanoma growth in mice. Melanoma Res. 2012, 22, 225-235. [CrossRef] 
16. Mehta, N.; Krepinsky, J.C. The emerging role of activins in renal disease. Curr. Opin. Nephrol. Hypertens. 2020, $29,136-144$. [CrossRef]

17. Namwanje, M.; Brown, C.W. Activins and Inhibins: Roles in Development, Physiology, and Disease. Cold Spring Harb. Perspect. Biol. 2016, 8, a021881. [CrossRef]

18. Werner, S.; Alzheimer, C. Roles of activin in tissue repair, fibrosis, and inflammatory disease. Cytokine Growth Factor Rev. 2006, 17, 157-171. [CrossRef] [PubMed]

19. Wada, W.; Kuwano, H.; Hasegawa, Y.; Kojima, I. The Dependence of Transforming Growth Factor- $\beta$-Induced Collagen Production on Autocrine Factor Activin A in Hepatic Stellate Cells. Endocrinology 2004, 145, 2753-2759. [CrossRef] [PubMed]

20. Yamashita, S.; Maeshima, A.; Kojima, I.; Nojima, Y. Activin A Is a Potent Activator of Renal Interstitial Fibroblasts. J. Am. Soc. Nephrol. 2004, 15, 91-101. [CrossRef]

21. Aoki, F.; Kurabayashi, M.; Hasegawa, Y.; Kojima, I. Attenuation of Bleomycin-induced Pulmonary Fibrosis by Follistatin. Am. J. Respir. Crit. Care Med. 2005, 172, 713-720. [CrossRef] [PubMed]

22. Chang, A.S.; Hathaway, C.K.; Smithies, O.; Kakoki, M. Transforming growth factor- $\beta 1$ and diabetic nephropathy. Am. J. Physiol. Physiol. 2016, 310, F689-F696. [CrossRef] [PubMed]

23. Ren, X.-J.; Guan, G.-J.; Liu, G.; Zhang, T.; Liu, G.-H. Effect of activin A on tubulointerstitial fibrosis in diabetic nephropathy. Nephrology 2009, 14, 311-320. [CrossRef]

24. Zhang, L.; Deng, M.; Parthasarathy, R.; Wang, L.; Mongan, M.; Molkentin, J.D.; Zheng, Y.; Xia, Y. MEKK1 Transduces Activin Signals in Keratinocytes to Induce Actin Stress Fiber Formation and Migration. Mol. Cell. Biol. 2005, 25, 60-65. [CrossRef] [PubMed]

25. Zhang, M.; Liu, N.-Y.; Wang, X.-E.; Chen, Y.-H.; Li, Q.-L.; Lu, K.-R.; Sun, L.; Jia, Q.; Zhang, L.; Zhang, L. Activin B Promotes Epithelial Wound Healing In Vivo through RhoA-JNK Signaling Pathway. PLoS ONE 2011, 6, e25143. [CrossRef]

26. Xu, T.; Wu, M.; Feng, J.; Lin, X.; Gu, Z. RhoA/Rho kinase signaling regulates transforming growth factor- $\beta 1$-induced chondrogenesis and actin organization of synovium-derived mesenchymal stem cells through interaction with the Smad pathway. Int. J. Mol. Med. 2012, 30, 1119-1125. [CrossRef]

27. Chang, C.-J.; Minei, R.; Sato, T.; Taniguchi, A. The Influence of a Nanopatterned Scaffold that Mimics Abnormal Renal Mesangial Matrix on Mesangial Cell Behavior. Int. J. Mol. Sci. 2019, 20, 5349. [CrossRef]

28. Fan, L.; Sebe, A.; Péterfi, Z.; Masszi, A.; Thirone, A.C.P.; Rotstein, O.D.; Nakano, H.; McCulloch, C.A.; Szászi, K.; Mucsi, I.; et al. Cell Contact-dependent Regulation of Epithelial-Myofibroblast Transition via the Rho-Rho Kinase-Phospho-Myosin Pathway. Mol. Biol. Cell 2007, 18, 1083-1097. [CrossRef] [PubMed]

29. Zhu, G.; Lee, A.S. Role of the unfolded protein response, GRP78 and GRP94 in organ homeostasis. J. Cell. Physiol. 2015, 230, 1413-1420. [CrossRef] [PubMed]

30. Gonzalez-Gronow, M.; Selim, M.A.; Papalas, J.; Pizzo, S.V. GRP78: A Multifunctional Receptor on the Cell Surface. Antioxid. Redox Signal. 2009, 11, 2299-2306. [CrossRef]

31. Gopal, U.; Mowery, Y.; Young, K.; Pizzo, S.V. Targeting cell surface GRP78 enhances pancreatic cancer radiosensitivity through YAP/TAZ protein signaling. J. Biol. Chem. 2019, 294, 13939-13952. [CrossRef]

32. Misra, U.K.; Gonzalez-Gronow, M.; Gawdi, G.; Pizzo, S.V. The Role of MTJ-1 in Cell Surface Translocation of GRP78, a Receptor for $\alpha 2$-Macroglobulin-Dependent Signaling. J. Immunol. 2005, 174, 2092-2097. [CrossRef]

33. Olayioye, M.A.; Noll, B.; Hausser, A. Spatiotemporal Control of Intracellular Membrane Trafficking by Rho GTPases. Cells 2019, 8, 1478. [CrossRef] [PubMed]

34. Nagai, Y.; Matoba, K.; Kawanami, D.; Takeda, Y.; Akamine, T.; Ishizawa, S.; Kanazawa, Y.; Yokota, T.; Utsunomiya, K.; Nishimura, R. ROCK2 regulates TGF- $\beta$-induced expression of CTGF and profibrotic genes via NF- $\kappa \mathrm{B}$ and cytoskeleton dynamics in mesangial cells. Am. J. Physiol. Physiol. 2019, 317, F839-F851. [CrossRef]

35. Reidy, K.; Kang, H.M.; Hostetter, T.; Susztak, K. Molecular mechanisms of diabetic kidney disease. J. Clin. Investig. 2014, 124, 2333-2340. [CrossRef] [PubMed]

36. Gojo, A.; Utsunomiya, K.; Taniguchi, K.; Yokota, T.; Ishizawa, S.; Kanazawa, Y.; Kurata, H.; Tajima, N. The Rho-kinase inhibitor fasudil, attenuates diabetic nephropathy in streptozotocin-induced diabetic rats. Eur. J. Pharmacol. 2007, 568, 242-247. [CrossRef]

37. Kikuchi, Y.; Yamada, M.; Imakiire, T.; Kushiyama, T.; Higashi, K.; Hyodo, N.; Yamamoto, K.; Oda, T.; Suzuki, S.; Miura, S. A Rho-kinase inhibitor, fasudil, prevents development of diabetes and nephropathy in insulin-resistant diabetic rats. J. Endocrinol. 2007, 192, 595-603. [CrossRef] [PubMed]

38. Davies, S.P.; Reddy, H.; Caivano, M.; Cohen, P. Specificity and mechanism of action of some commonly used protein kinase inhibitors. Biochem. J. 2000, 351, 95-105. [CrossRef]

39. Zhou, L.; Liu, F.; Huang, X.R.; Liu, F.; Chen, H.-Y.; Chung, A.C.; Shi, J.; Wei, L.; Lan, H.Y.; Fu, P. Amelioration of Albuminuria in ROCK1 Knockout Mice with Streptozotocin-Induced Diabetic Kidney Disease. Am. J. Nephrol. 2011, 34, 468-475. [CrossRef]

40. Wang, W.; Wang, Y.; Long, J.; Wang, J.; Haudek, S.B.; Overbeek, P.; Chang, B.H.; Schumacker, P.T.; Danesh, F.R. Mitochondrial Fission Triggered by Hyperglycemia Is Mediated by ROCK1 Activation in Podocytes and Endothelial Cells. Cell Metab. 2012, 15, 186-200. [CrossRef]

41. Wang, L.; Ellis, M.J.; Gomez, J.A.; Eisner, W.; Fennell, W.; Howell, D.N.; Ruiz, P.; Fields, T.A.; Spurney, R.F. Mechanisms of the proteinuria induced by Rho GTPases. Kidney Int. 2012, 81, 1075-1085. [CrossRef] 
42. Warren, A.M.; Knudsen, S.T.; Cooper, M.E. Diabetic nephropathy: An insight into molecular mechanisms and emerging therapies. Expert Opin. Ther. Targets 2019, 23, 579-591. [CrossRef]

43. Zhang, K.; Zhang, H.; Xiang, H.; Liu, J.; Liu, Y.; Zhang, X.; Wang, J.; Tang, Y. TGF- $\beta 1$ induces the dissolution of tight junctions in human renal proximal tubular cells: Role of the RhoA/ROCK signaling pathway. Int. J. Mol. Med. 2013, 32, 464-468. [CrossRef] [PubMed]

44. Voelker, J.; Berg, P.H.; Sheetz, M.; Duffin, K.; Shen, T.; Moser, B.; Greene, T.; Blumenthal, S.S.; Rychlik, I.; Yagil, Y.; et al. Anti-TGF- 31 Antibody Therapy in Patients with Diabetic Nephropathy. J. Am. Soc. Nephrol. 2017, 28, 953-962. [CrossRef] [PubMed]

45. Wang, X.; Tang, P.; Guo, F.; Zhang, M.; Chen, Y.; Yan, Y.; Tian, Z.; Xu, P.; Zhang, L.; Zhang, L.; et al. RhoA regulates Activin B-induced stress fiber formation and migration of bone marrow-derived mesenchymal stromal cell through distinct signaling. Biochim. Biophys. Acta Gen. Subj. 2017, 1861, 3011-3018. [CrossRef] [PubMed]

46. Liu, L.-J.; Yao, F.-J.; Lu, G.-H.; Xu, C.-G.; Xu, Z.; Tang, K.; Cheng, Y.-J.; Gao, X.-R.; Wu, S.-H. The Role of the Rho/ROCK Pathway in Ang II and TGF- $\beta 1-I n d u c e d$ Atrial Remodeling. PLoS ONE 2016, 11, e0161625. [CrossRef] [PubMed]

47. Wu, D.; Peng, F.; Zhang, B.; Ingram, A.J.; Gao, B.; Krepinsky, J.C. Collagen I induction by high glucose levels is mediated by epidermal growth factor receptor and phosphoinositide 3-kinase/Akt signalling in mesangial cells. Diabetologia 2007, 50, 2008-2018. [CrossRef]

48. Wang, J.; Xu, J.; Zhao, X.; Xie, W.; Wang, H.; Kong, H. Fasudil inhibits neutrophil-endothelial cell interactions by regulating the expressions of GRP78 and BMPR2. Exp. Cell Res. 2018, 365, 97-105. [CrossRef] 